\title{
Semi-transparent photovoltaic glazing based on electrodeposited CIGS solar cells on patterned molybdenum/glass substrates
}

\author{
Tarik Sidali ${ }^{1}$, Adrien Bou ${ }^{1}$, Damien Coutancier ${ }^{2}$, Elisabeth Chassaing ${ }^{2}$, Bertrand Theys $^{2}$, Damien Barakel ${ }^{3}$, \\ Richard Garuz ${ }^{3}$, Pierre-Yves Thoulon ${ }^{1}$, and Daniel Lincot ${ }^{2, *}$ \\ ${ }^{1}$ Crosslux, 1200 Avenue Olivier Perroy, 13790 Rousset, France \\ ${ }^{2}$ CNRS, Institut Photovoltaïque Ile de France (IPVF), 30 Route Départementale 128, 91120 Palaiseau, France \\ ${ }^{3}$ IM2NP, Avenue Escadrille Normandie Niemen, Case 231, 13397 Marseille Cedex 20, France
}

Received: 25 August 2017 / Accepted: 13 December 2017

\begin{abstract}
In this paper, a new way of preparing semi-transparent solar cells using $\mathrm{Cu}\left(\mathrm{In}_{1-\mathrm{x}} \mathrm{Ga}_{\mathrm{x}}\right) \mathrm{Se}_{2}(\mathrm{CIGS})$ chalcopyrite semiconductors as absorbers for BIPV applications is presented. The key to the elaboration process consists in the co-electrodeposition of $\mathrm{Cu}-\mathrm{In}-\mathrm{Ga}$ mixed oxides on submillimetric hole-patterned molybdenum substrate, followed by thermal reduction to metallic alloys and selenisation. This method has the advantage of being a selective deposition technique where the thin film growth is carried out only on Mo covered areas. Thus, after annealing, the transparency of the sample is always preserved, allowing light to pass through the device. A complete device $\left(5 \times 5 \mathrm{~cm}^{2}\right)$ with $535 \mu \mathrm{m}$ diameter holes and total glass aperture of around $35 \%$ shows an open circuit voltage $\left(\mathrm{V}_{\mathrm{OC}}\right)$ of $400 \mathrm{mV}$. Locally, the $\mathrm{I}-\mathrm{V}$ curves reveal a maximum efficiency of $7.7 \%, \mathrm{~V}_{\mathrm{OC}}$ of $460 \mathrm{mV}, \mathrm{J}_{\mathrm{SC}}$ of $24 \mathrm{~mA} . \mathrm{cm}^{-2}$ in an area of $0.1 \mathrm{~cm}^{2}$ with $35 \%$ aperture. This efficiency on the semi-transparent area is equivalent to a record efficiency of $11.9 \%$ by taking into account only the effective area.
\end{abstract}

Keywords: PV glass / BIPV / CIGS thin films / semi-transparent solar cell / electrodeposition / see-through solar cell / submillimetric pattern / bottom-up solar cell

\section{Introduction}

Photovoltaic glass (PV glass) with controlled transparency is an emerging application in the field of building integrated photovoltaics (BIPV) which is also a new way to produce zero energy buildings. Classically, PV glass is manufactured according to two methods: from a naturally semitransparent material, by precisely controlling its thickness, or by structuring an opaque thin film material.

Currently, the second solution is the most widespread because it uses technologies with high efficiencies and good reliability, and may exhibit a neutral spectral rendering. This is achieved using crystalline silicon cells spaced apart and laminated in between two sheets of glass. Even if this solution is working and of a high efficiency, this glazing is aesthetically inferior, and quickly reaches its limits from an architectural and thermal point of view.

To perfect the aesthetic factor and play on transparency of the crystalline silicon, Sunways [1] has worked on the industrialization of a laser structuration that allows

\footnotetext{
* e-mail: daniel.lincot@chimie-paristech.fr
}

transparencies between 20 and $30 \%$ with $2-5 \mathrm{~mm}$ holes. Then, from a certain viewing distance (superior to few meters) from inside to outside of the building windows, the human eyes are unable to distinguish the holes, giving PV glass a "see-through" or tinted appearance. But, the difficulties to realize smaller holes without degrading the PV performances, excessive time processing, and loss of the ablated materials have led to the ending of these studies.

Thin film solar cell technologies are also well adapted for such PV glass applications. Several materials have been investigated during past decades: hydrogenated amorphous silicon cells (a-Si:H), cadmium telluride cells (CdTe), copper indium gallium diselenide cells (CIGS) and all organic solar cells (various materials). The older solution with a-Si:H presents a low efficiency of around $7 \%$ on large module (record of $13.6 \%$ efficiency for cell efficiency in a multijunction configuration [2], much lower than CIGS and CdTe single junction counterparts) with transparencies rarely higher than $20 \%$ and an amber color. Creation of patterns by photolithography and laser on a-Si:H module to be able to see through the panel allows more neutral color by capturing the whole solar spectrum on the aperture area, but the loss in efficiency limits the transparency to a low value $(\sim 30 \%)$ $[3-5]$. For example, two of the major industrial actors on this 


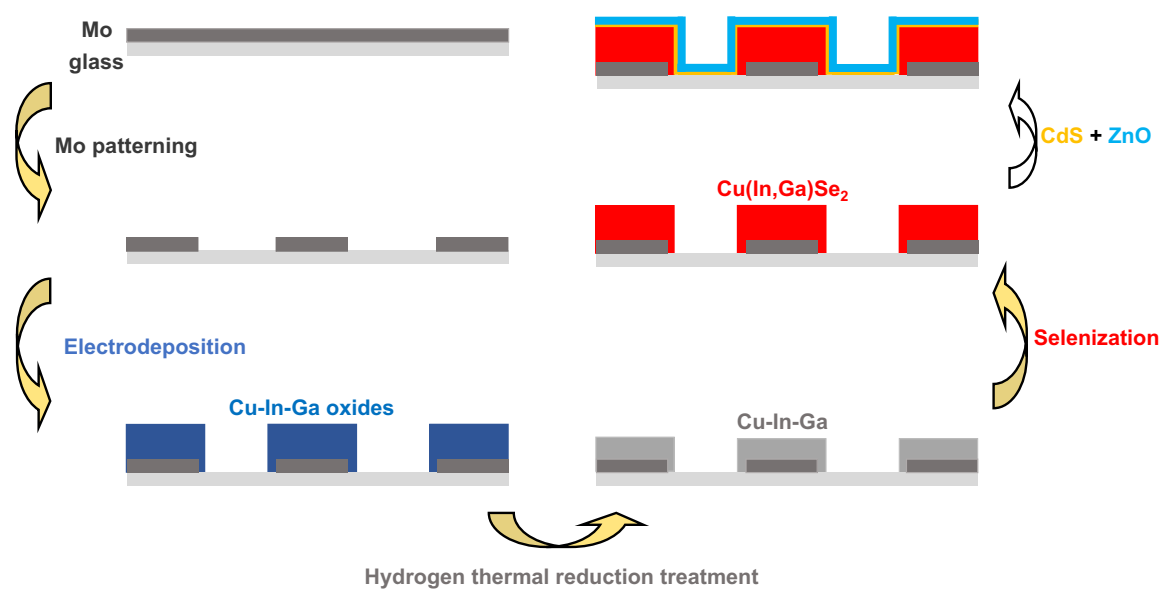

Fig. 1. Processing steps for the fabrication of semi-transparent CIGS solar cells based on the Glass/patterned Mo/CIGS/CdS/ZnO architecture.

technology, OnyxSolar and PolySolar, announce output efficiencies around $3 \%$ at $30 \%$ of transparency.

The CdTe technology has the advantage to have a higher efficiency than a-Si:H (around $22 \%$ in cell [2] and $18.6 \%$ in industrial module [6]). CdTe can be deposited as semitransparent thin film or be structured when deposited as a thicker opaque film. For example, PolySolar presents efficiencies between 7 and $8 \%$ for solar windows with a visible light transmission of $30 \%$ [4]. The problem of the toxicity of cadmium remains a drawback to the deployment of CdTe in buildings. CIGS presents record cell efficiencies up to $22.6 \%$ [7], even higher than CdTe, with module efficiencies comparable to CdTe at about $18 \%$ [8]. The CIGS technology has the advantage to be able to work with minute amount of cadmium (30-50 nm CdS buffer layer) as used in the record cell and by several module manufacturers, and more and more without cadmium by the progressive substitution of CdS buffer layers by ZnS based buffer layers, in particular by the leading industrial manufacturer [9].

Finally, the organic solution, by using low cost materials and production methods (roll-to-roll) at low thicknesses $(<500 \mathrm{~nm}$ for the whole stack), allows homogeneous transparencies by playing simply on the thicknesses of the different materials. Nevertheless, from an industrial point of view, this solution is not yet mature and still presents limitations due to lifespan and efficiency (record of $12-13 \%$ in cell [2], in strong evolution since 2007).

The CIGS technology is very promising for entering into this PV glass field since it can deliver high efficiency solar cells $(22.6 \%$ record) or modules and already exists in the market for power applications. This is why the use of CIGS, a long lifespan and high efficiency technology, is a very adequate solution for semi-transparent $\mathrm{PV}$ glazing and is the object of our study. Nevertheless, existing structuration approaches remain limited to drilling holes in the whole stack at the end of the module manufacturing process, with difficulties to achieve submillimetric patterns, limiting the flexibility of the process, the quality of the visual rendering and the execution speed.

Localized deposition techniques can naturally allow growth on defined areas without masking. Such self-aligned growth techniques include electrodeposition or ink pro- cesses. In this study, we chose electrodeposited solar cells. Electrodeposition, which has already been proven to be an efficient industrial method for standard modules, allows efficiencies up to $14 \%$ [10] in module and $17.3 \%$ in cell. By adopting bottom-up solar cell synthesis via localized growth processes, we have the advantage of drastically limiting raw material consumption, in comparison with approaches based on post-deposition patterning. This is of crucial importance to limit the price of the final $\mathrm{PV}$ glass and also in the perspective of improving the environmental impact by limiting the use of rare elements (indium and gallium). We also have the possibility to reduce the pattern size largely under the millimeter without degrading the PV performance. This approach has been recently successfully studied for CIGS electrochemical deposition on one millimeter wide molybdenum lines in view of CIGS microcell applications under concentration [11].

The objective of this paper is to describe our electrodeposited bottom-up solar cell synthesis on laser-structured glass/molybdenum substrates with submillimeter hole patterns fully compatible with see-through PV windows for BIPV application.

\section{Experimental methods}

The approach to create glass aperture in the classical glass/ $\mathrm{Mo} / \mathrm{CIGS} /$ buffer $/ \mathrm{ZnO} / \mathrm{AZO}$ structure is to start from a laser patterned Mo back contact (900 nm deposited by DC sputtering), and selectively deposit the CIGS layer only on the Mo covered areas (Fig. 1). A key method allowing such selective deposition of CIGS is electrodeposition. Electrodeposited CIGS solar cells have been prepared in the classical configuration on glass/Mo substrate using an electrodeposition route introduced recently in the field, and known as the oxide route [12]. It consists in depositing a layer of mixed copper, indium and gallium oxides/ hydroxides by cathodic deposition from an aqueous solution of nitrate salts. Then the oxides are reduced to metals through hydrogen thermal treatment, followed by selenisation to form CIGS (Fig. 1). A record efficiency of $12.4 \%$ [13] has been obtained with mean values around 


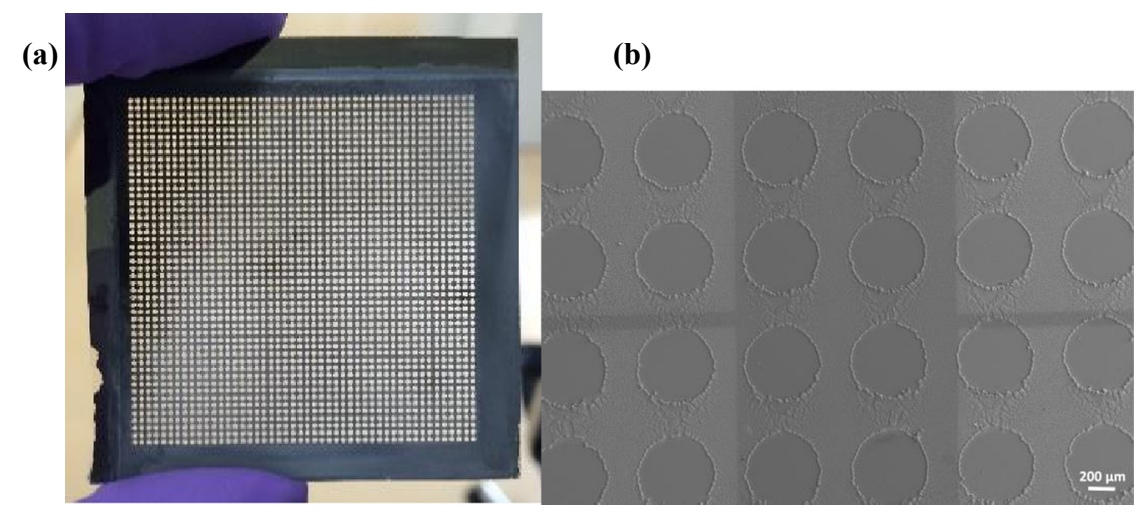

Fig. 2. (a) Glass/Mo substrate $\left(5 \times 5 \mathrm{~cm}^{2}\right)$ with laser patterned Mo back contact zone $\left(4 \times 4 \mathrm{~cm}^{2}\right)$ in the center after the electrodeposition of CIGS. (b) SEM details of the structured Mo surface with conformal CIGS cells giving the size of the holes of the pattern.

$11 \%$ [14]. This process has been adapted for the deposition on patterned Mo substrates. The deposition have been carried out in an aqueous electrolyte at room temperature containing $13 \mathrm{mM}$ of copper(II) nitrate, $20 \mathrm{mM}$ of indium nitrate and $10 \mathrm{mM}$ of gallium nitrate, acidified by nitric acid addition ( $\mathrm{pH}$ 1.8). The bath composition was chosen to lead to molar ratios $\mathrm{Cu} /(\mathrm{In}+\mathrm{Ga})$ and $\mathrm{Ga} /(\mathrm{Ga}+\mathrm{In})$ of about 0.9 and 0.3 , respectively to lead to good quality absorbers. The electrochemical set up was Biologic VSP potentiostat operating in the three electrode configuration at a fixed applied potential versus a calomel reference electrode. Typical patterns are $\sim 535 \mu \mathrm{m}$ diameter holes with $\sim 775 \mu \mathrm{m}$ spacing, leading to $\sim 240 \mu \mathrm{m}$ wide Mo channels at minimum (Fig. 2) and total glass aperture of $\sim 35 \%$. The solar cells are completed by the deposition of $50 \mathrm{~nm}$ of CdS buffer layer by chemical bath deposition, and a window layer composed of $80 \mathrm{~nm}$ intrinsic $\mathrm{ZnO}$ and $400 \mathrm{~nm}$ Al-doped $\mathrm{ZnO}$ by RF sputtering. Optoelectronic properties of devices were determined by current-voltage characteristics measured under standard AM 1.5G conditions using an AAA class solar simulator (Newport); a homemade spectral response (EQE) setup was used to determine the short circuit current in full and semitransparent areas of the device. Photocurrent mapping has been realized by means of specific LBIC equipment dedicated to large area studies and developed in the framework of the Equipex ANR project called DURASOL. This homemade LBIC can perform large-scale photocurrent mappings $(1.7 \mathrm{~m} \times 1.2 \mathrm{~m}$, resolution: $1 \mathrm{~mm})$ as well as small-scale photocurrent mappings $(1 \mathrm{~mm} \times 1 \mathrm{~mm}$, resolution: $10 \mu \mathrm{m})$. The light source is a polychromatic white light but it can also be monochromatic in the visible range from 400 to $1200 \mathrm{~nm}$. In this work, the mappings were obtained with the white light and the small scale and highresolution mode has been used.

\section{Results and discussion}

We succeeded in obtaining conformal deposits of CIGS on the patterned Glass/Mo substrates as shown in Figures 2 and 3. Figure 3 shows the surface morphology at the different steps of the production of the CIGS layer.
Globally, we can note that the pattern size is preserved in each step validating the bottom-up technique on submillimeter patterns. The SEM images, presented in Figure 3a, show that the patterned Mo is completely covered by the $\mathrm{Cu}$-In-Ga oxide/hydroxide precursor film. No deposition inside the holes can be observed; thereby the transparency of the device is preserved. The deposition is homogeneous with some cracks resulting from partial dehydration of the film. The composition will allow obtaining good performance of CIGS with $\mathrm{Cu} /(\mathrm{In}+\mathrm{Ga})$ and $\mathrm{Ga} /(\mathrm{In}+\mathrm{Ga})$ ratios of 0.77 and 0.34 , respectively. Differences are observed with the deposition on plain Mo substrates since the diffusion regimes from the solution are different [11], requiring some adjustment in the deposition parameters. After reduction heat treatment under flowing pure hydrogen (Fig. 3b), again, no deposition is observed inside the holes. The precursor has a metallic aspect, which is confirmed by XRD with the formation of metallic indium and a metallic alloy of CuInGa [14]. The CGI and GGI ratios, around 0.84 and 0.30 , respectively, change a little bit, probably due to loss of indium by evaporation during annealing. After selenisation (Fig. 3c), the transparency of the sample is also preserved with no deposition inside the holes. The XRD analysis shows two phases: CIS on the top and CIGS [14] with a GGI ratio of 0.25 . This explains the decrease in the GGI ratio probably related to the gallium diffusion at the back contact during this annealing step [14]. We can note that this gradient with an increase of gallium towards the Mo contact is very beneficial to the cell performances.

Figure 4 presents SEM cross section of the complete CIGS solar cell in full area between holes. The CIGS thickness is about $2.6 \mu \mathrm{m}$ with large grains near the front contact and small grains near the molybdenum back contact which is due to the gallium diffusion [14].

Solar cells characterizations were performed to determine the PV properties. On Figure 5, a photograph is shown of a $5 \times 5 \mathrm{~cm}^{2}$ sample with a $\mathrm{Ni} / \mathrm{Al}$ contacting grid with $5 \mathrm{~mm}$ distance between the lines.

This configuration allows carrying out spectral response measurements on localized zones of the substrate using modulated illumination. Figure 6 shows spectral response measurements on a patterned zone and on a plain one. The 
(a)

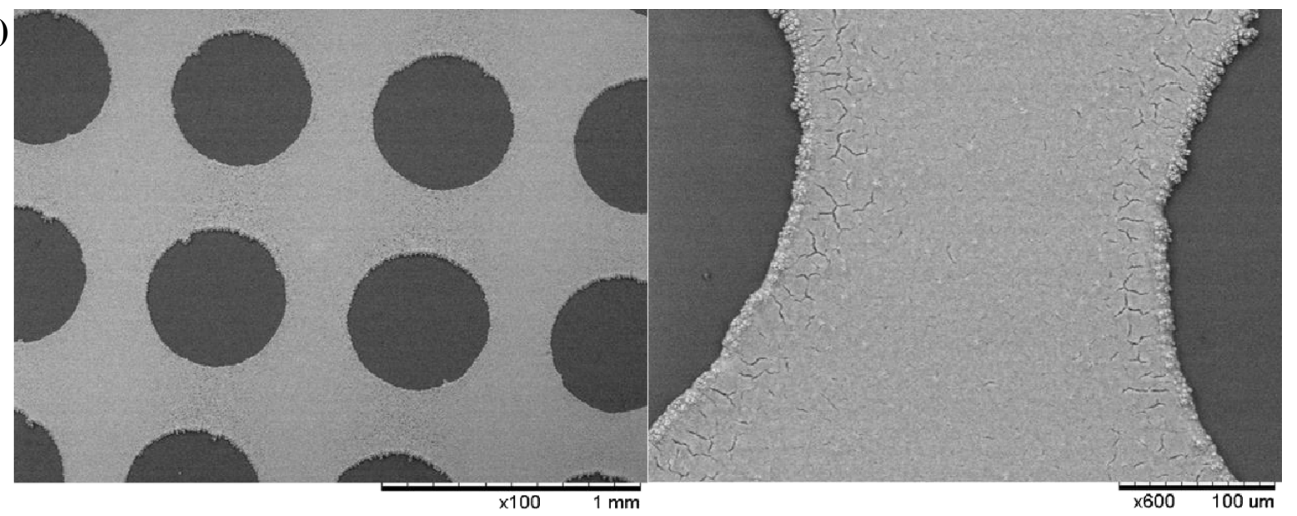

(b)

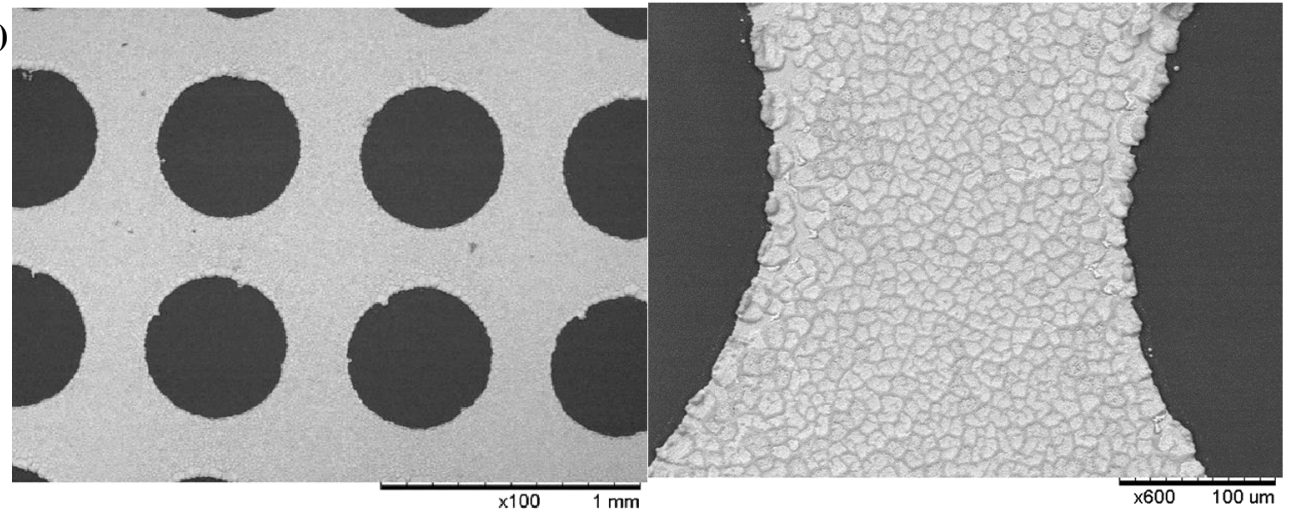

(c)
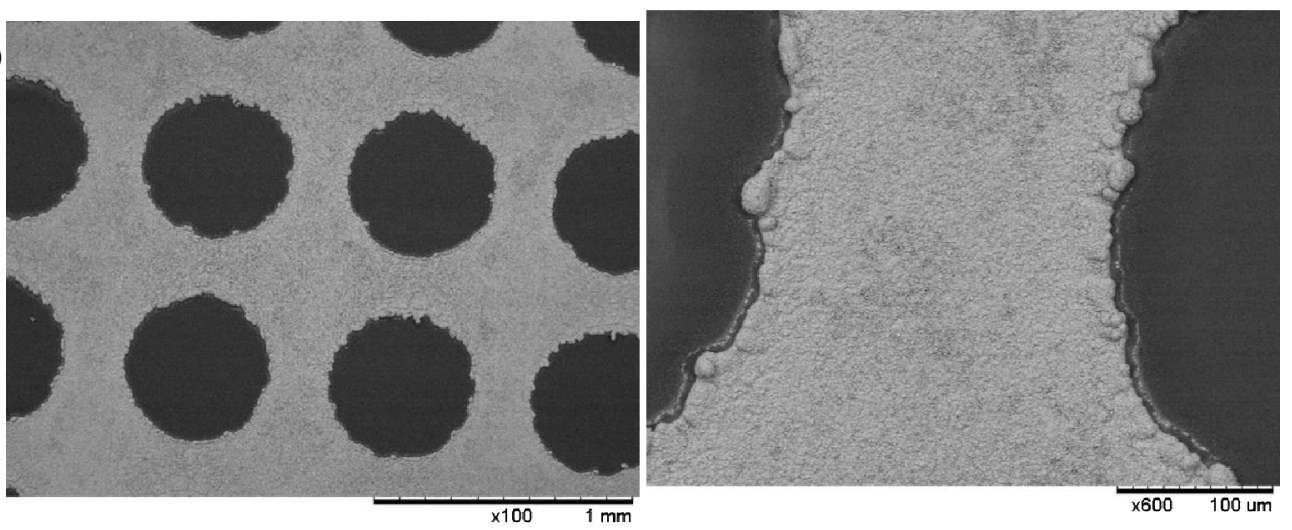

Fig. 3. (a) SEM image of localized co-electrodeposited mixed hydroxides thin layer $\left(\mathrm{Cu}(\mathrm{OH})_{2}, \mathrm{In}(\mathrm{OH})_{3}, \mathrm{GaOOH}\right)-(\mathrm{b}) \mathrm{SEM}$ observation of the surface of $\mathrm{Cu}-\mathrm{In}-\mathrm{Ga}$ after $\mathrm{H}_{2}$ annealing at $520^{\circ} \mathrm{C}-$ (c) SEM observation of the surface of $\mathrm{Cu}(\mathrm{In}, \mathrm{Ga}) \mathrm{Se}{ }_{2}$ after selenisation annealing at $580^{\circ} \mathrm{C}-$ [for each, left: view of several patterns ; right: zoom on a channel between two holes].

CdS/i:ZnO/ZnO:Al

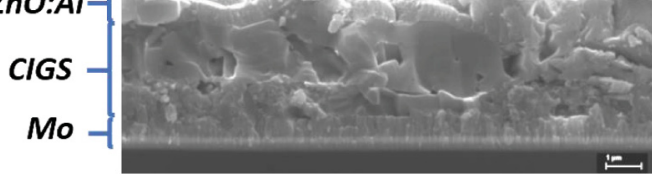

Fig. 4. SEM cross section of the complete CIGS solar cell. quantum efficiency in the plain zone is typical of good quality CIGS solar cells, with a large plateau with quantum efficiencies approaching $80 \%$, which is expected for cells without antireflective coating. The absorption front in the high wavelength range is abrupt indicating a good electronic quality. The band gap is close to that of pure CIS which is coherent with the XRD experiments. In the case of a structured zone, the plateau on the EQE is about $50 \%$. This corresponds to about $65 \%$ of the EQE obtained on the plain area and is a direct consequence of the characteristic of the textured Mo substrate with $35 \%$ transparency. The spectral response obtained by using this 
(a)

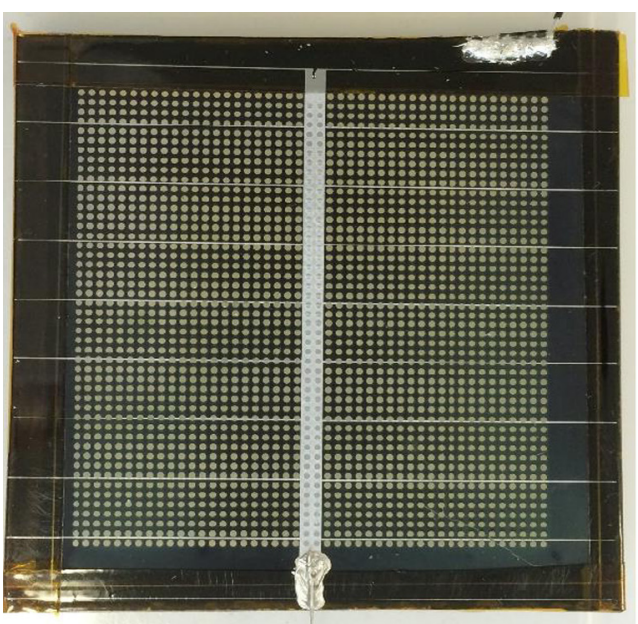

(b)

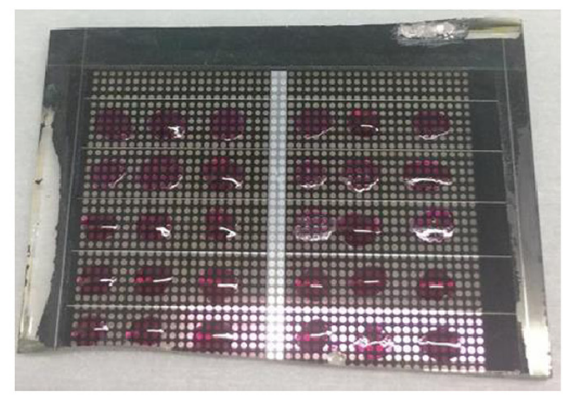

Fig. 5. (a) View of a completed device over the $5 \times 5 \mathrm{~cm}^{2}$ patterned substrate, with $\mathrm{Ni} / \mathrm{Al}$ contacting grid deposited on top of the $\mathrm{ZnO}$ layer, (b) and on a part of this sample the preparation of isolated smalls cells with varnish (around $0.1 \mathrm{~cm}^{2}$ ).

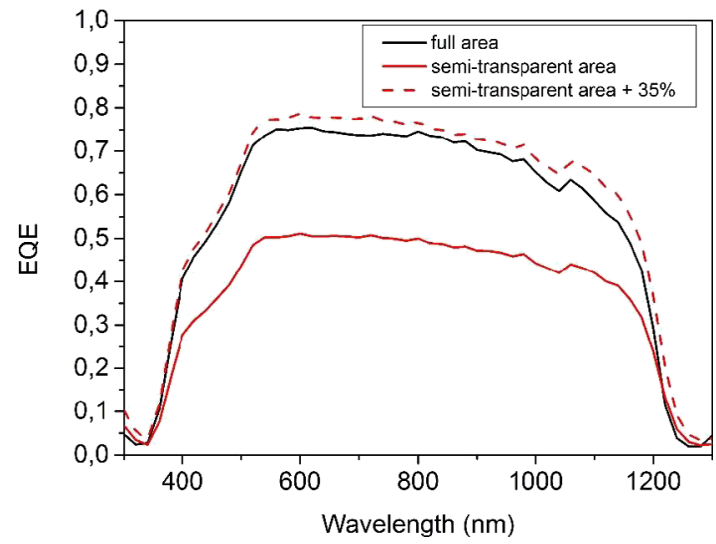

Fig. 6. EQE curves in full (black) and semi-transparent (red) areas.

correction factor is shown in the figure and superposes well with that of the plain substrate. This demonstrates that the PV characteristics of the internal CIGS junction are not affected by the structuration of the substrate which is an important information for the relevance of the technology.

The expected photocurrent density under standard AM1.5 $1000 \mathrm{~W} / \mathrm{m}^{2}$ illumination has been calculated by the integration of quantum efficiencies under the solar spectrum. This leads, from Figure 6 , to 31.1 and $21.3 \mathrm{~mA} / \mathrm{cm}^{2}$ for plain and semi-transparent areas respectively.

Figure 7a presents the I-V curves of the complete device $\left(5 \times 5 \mathrm{~cm}^{2}\right)$ under illumination and in darkness.

The curve under illumination leads to an open circuit potential of $400 \mathrm{mV}$, a short circuit current around $9 \mathrm{~mA} / \mathrm{cm}^{2}$ and a fill factor of $27 \%$. While the open circuit voltage is correct, the short circuit current density and the fill factor are much lower than expected, in particular for the photocurrent. As a consequence the conversion efficiency is very low at the percentage level. A shunt resistance effect can be excluded since the slope on the I-V curve in the dark at the origin is much lower than that under illumination, corresponding to a shunt resistance value about $750 \Omega . \mathrm{cm}^{2}$. On the contrary, the behavior under illumination fits with a strong series resistance effect which is also visible on the $\mathrm{I}-\mathrm{V}$ curve in dark with the quasi linear variation in the positive polarization domain. To test this hypothesis, measurements have been carried out on small solar cells distributed all over the substrate, with areas around $10 \mathrm{~mm}^{2}$ (Fig. 5b). The results are shown in Figure $7 \mathrm{~b}$ for a series of cells along the width of the substrate in a structured Mo zone. It appears that the I-V curves are of much better quality with the suppression of the strong detrimental series resistance effect. The PV parameters now reach for the best cell a $\mathrm{V}_{\mathrm{OC}}$ of $460 \mathrm{mV}$, a $\mathrm{J}_{\mathrm{SC}}$ of $24.4 \mathrm{~mA} / \mathrm{cm}^{2}$ and a fill factor of $56 \%$. The $\mathrm{J}_{\mathrm{SC}}$ value is now consistent with that expected from the spectral response analysis. The corresponding efficiency is $7.7 \%$. Taking into account the transparency factor of $35 \%$ leads to an equivalent efficiency on the plain substrate of $11.9 \%$, which is close to the record efficiencies previously obtained on plain substrates for this process $[13,14]$. This demonstrates that there are no significant losses due to the structuration of the molybdenum back contact. This is key result for the validity of this approach for high efficiency PV glazing.

Further experiments have been carried out to map the properties of the $5 \times 5 \mathrm{~cm}^{2}$ device and shown in Figure 8 . Figure $8 \mathrm{a}$ shows an LBIC mapping of the whole device corresponding to the conditions of Figure 7a. We can observe the photocurrent generation on the zones covered with CIGS over the whole substrate. However the amplitude of the LBIC signal is strongly varying from bottom to top. This indicates losses along the vertical direction and confirms the series resistance effect evidenced from the global I-V curve. It can be related to series resistance in the $\mathrm{ZnO}$ layer and to resistive $\mathrm{Ni} / \mathrm{Al}$ contact.

Mapping experiments (Fig. 8b) have been made after the formation of small isolated cells all over the substrate (Fig. 5b) corresponding to the I-V curves presented in Figure $7 \mathrm{~b}$. We can see a much more homogeneous and efficient PV response over the whole device, with efficiencies between about $5 \%$ and almost $8 \%$, with good performance even in the regions where the LBIC measurement shows low 

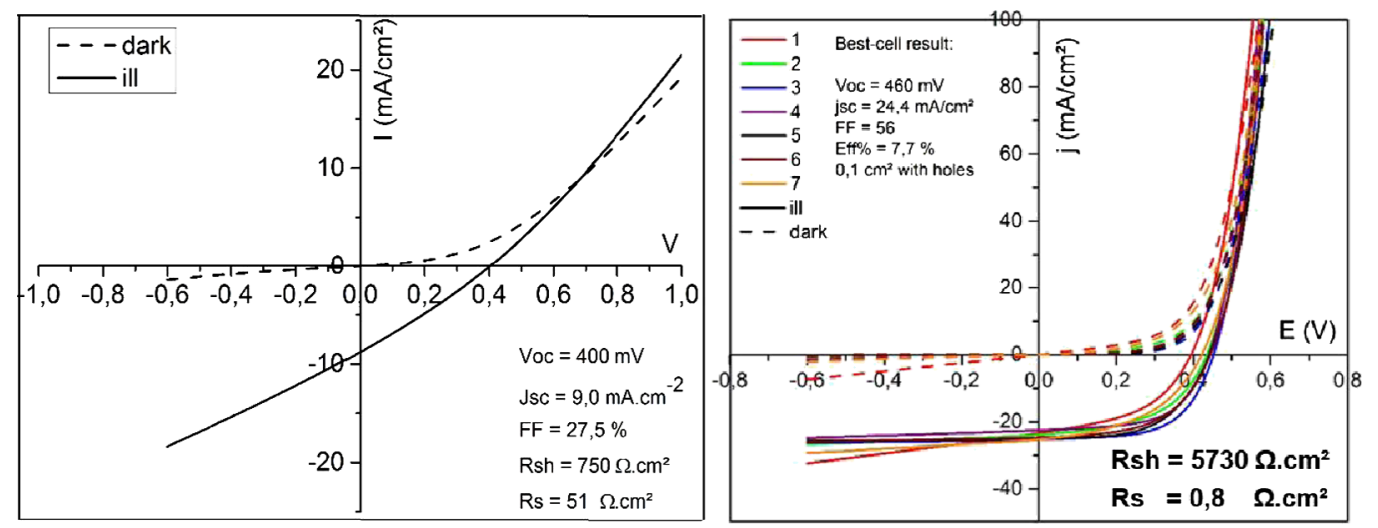

Fig. 7. (a) I-V curves on complete device; (b) localized I-V curves on $0.1 \mathrm{~cm}^{2}$ surfaces with holes.
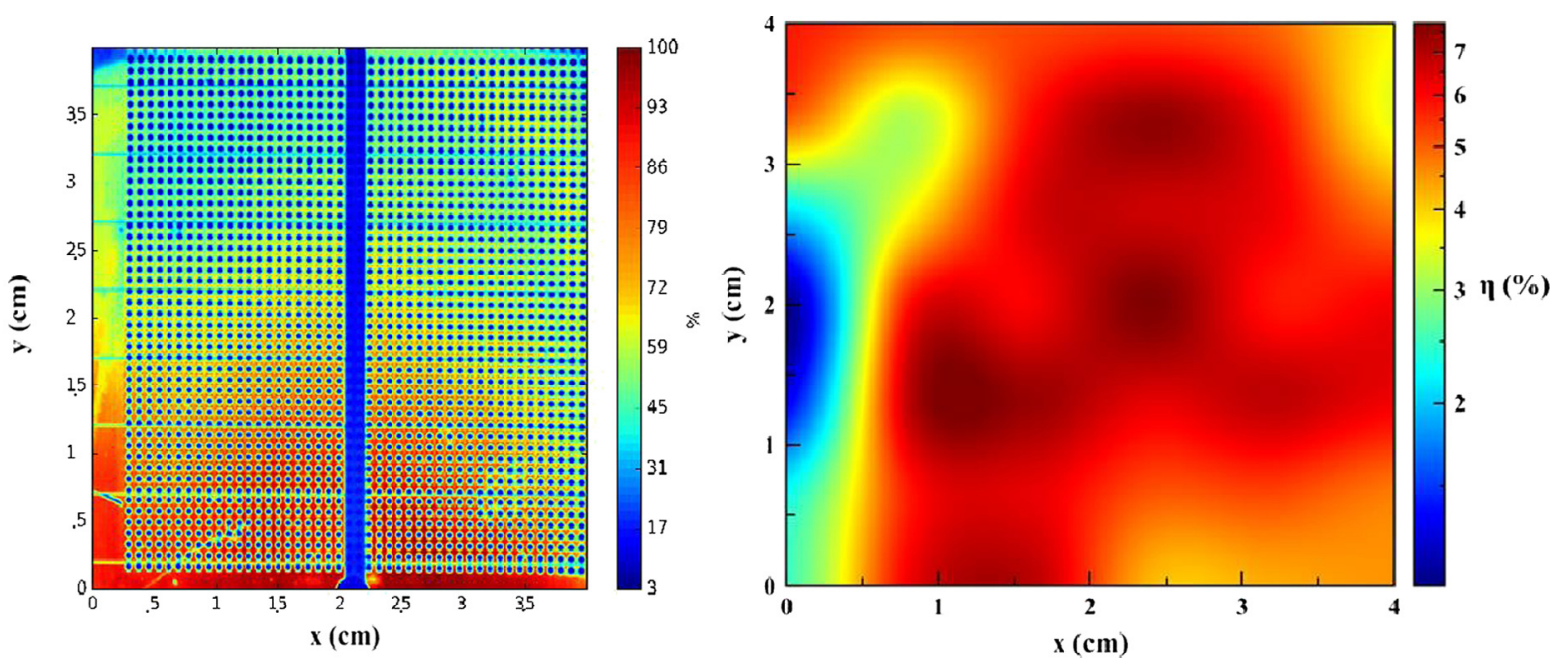

Fig. 8. (a) LBIC measurements; (b) mapping of localized efficiencies.

collection of electrons. This confirms the high impact of the $\mathrm{ZnO}$ layer on series resistances over the whole device area.

\section{Conclusion}

In this paper, we have presented a successful experimental process to prepare semi-transparent solar cells using $\mathrm{Cu}$ $\left(\mathrm{In}_{1-\mathrm{x}} \mathrm{Ga}_{\mathrm{x}}\right) \mathrm{Se}_{2}$ (CIGS) chalcopyrite semiconductors as absorber for BIPV applications via electrodeposition on structured Mo substrates with submillimetric patterns.

We obtained a $7.7 \%$ efficiency value for a see-through solar cell with $35 \%$ of aperture area on glass corresponding to a Mo substrate comprising holes of about $535 \mu \mathrm{m}$ in diameter. This represents an equivalent efficiency of $11.9 \%$ for a solar cell on plain substrate, which is similar to the highest values previously achieved with this process. The transparency of the sample is preserved all along the process. These first results already represent the proof of concept of the electrodeposition approach for PV glazing. Next steps will be the optimization of this concept and the increase of the sample size $\left(15 \times 15 \mathrm{~cm}^{2}\right)$ to make an operational demonstrator device. Moreover, for industrial purposes, the electrodeposition process has the advantage of nicely scaling to larger device areas $\left(60 \times 120 \mathrm{~cm}^{2}\right.$ and beyond), as required for $\mathrm{PV}$ windows, which is the current development at Crosslux.

This work has been done in the frame of a collaboration contract between Crosslux and CNRS at IRDEP. The IRDEP team is acknowledged for its support.

We would like to thank Anne-Marie GONCALVES and Arnaud ETCHEBERRY from the Institut Lavoisier de Versailles (ILV) for their experimental support.

These results have been presented at PVTC 2017 in Marseille and partially presented at JNPV 2016.

\section{References}

1. P. Fath, S. Keller, A. Boueke, R. Kuhn, E. Bucher, in Conference Record of the Twenty-Eighth IEEE Photovoltaic Specialists Conference - 2000 (Cat. No.00CH37036), IEEE (2000), pp. $335-338$

2. Best research-Cell Efficiencies, National Renewable Energy Laboratory: www.nrel.gov/pv/assets/images/efficiencychart.png

3. A. Takeoka, S. Kouzuma, H. Tanaka, H. Inoue, K. Murata, M. Morizane, N. Nakamura, H. Nishiwaki, M. Ohnishi, S. Nakano, Y. Kuwano, Sol. Energy Mater. Sol. Cells 29, 243 (1993) 
4. Polysolar, Building Integrated Transparent Photovoltaic Glass, http://www.polysolar.co.uk

5. ASI Glass, http://www.schott.com/d/france/a753c14ec34c-4cf3-9289-90c790ec7da1/1.0/schott_asi_glass_bro chure fr.pdf

6. M.A. Green, Y. Hishikawa, W. Warta, E.D. Dunlop, D.H. Levi, J. Hohl-Ebinger, A.W.H. Ho-Baillie, Prog. Photovoltaics Res. Appl. 25, 668 (2017)

7. P. Jackson, R. Wuerz, D. Hariskos, E. Lotter, W. Witte, M. Powalla, Phys. Status Solidi - Rapid Res. Lett. 10, 583 (2016)

8. J. Nam, Y. Kang, D. Lee, J. Yang, Y.-S. Kim, C.B. Mo, S. Park, D. Kim, Prog. Photovoltaics Res. Appl. 24, 175 (2016)

9. K. Rui, Y. Takeshi, A. Shunsuke, H. Atsushi, F.T. Kong, K. Takuya, S. Hiroki, in 2016 IEEE 43th Photovolt. Spec.
Conf. PVSC 2016 Portland(OR) USA, June 2016 (2016), pp. 3-7

10. C. Broussillou, C. Viscogliosi, A. Rogee, S. Angle, P.P. Grand, S. Bodnar, C. Debauche, J.L. Allary, B. Bertrand, C. Guillou, L. Parissi, S. Coletti, in 2015 IEEE 42nd Photovoltaic Specialist Conference (PVSC), IEEE (2015), pp. 1-5.

11. A. Duchatelet, K. Nguyen, P.P. Grand, D. Lincot, M. Paire, Appl. Phys. Lett. 109, 253901 (2016)

12. A. Duchatelet, G. Savidand, N. Loones, E. Chassaing, D. Lincot, J. Electrochem. Soc. 161, D3120 (2014)

13. A. Duchatelet, T. Sidali, N. Loones, G. Savidand, E. Chassaing, D. Lincot, Sol. Energy Mater. Sol. Cells 119, $241(2013)$

14. T. Sidali, A. Duchatelet, E. Chassaing, D. Lincot, Thin Solid Films 582, 69 (2015)

Cite this article as: Tarik Sidali, Adrien Bou, Damien Coutancier, Elisabeth Chassaing, Bertrand Theys, Damien Barakel, Richard Garuz, Pierre-Yves Thoulon, Daniel Lincot, Semi-transparent photovoltaic glazing based on electrodeposited CIGS solar cells on patterned molybdenum/glass substrates, EPJ Photovoltaics 9, 2 (2018) 